\title{
Conceptual Blending and Slang Expressions in Hong Kong Cantonese
}

\author{
May L-Y Wong \\ The University of Hong Kong
}

\begin{abstract}
This paper seeks to examine nine slang words created newly in Cantonese, which started their life journey from the inventions of individuals and now constituting the established lexical means of expressing cultural conceptualizations. These slang expressions are analyzed with reference to the theory of conceptual integration (also known as "blending") developed in Fauconnier and Turner 2002. In the analysis, four different types of conceptual integration network (i.e., simplex networks, single-scope networks, double-scope, and multiple-scope networks) are used to unravel the increasingly complex systems of cognitive operations with which the "slang" blends are created. During the discussion of the conceptual integration networks here, we were able to see how elements and relations from familiar conceptualizations can be transformed into new and meaningful ones that align along with the changes in cultural conceptualizations. It is hoped that this study shows that, despite having wide applications in the English language, the blending theory can provide an integrated and coherent account of the cognitive mechanisms by which colloquial words are constructed and construed in terms of cultural experiences specific to a given non-Anglo locality.
\end{abstract}

\section{Keywords}

conceptual integration, conceptual blending, slang, Cantonese, Hong Kong culture

Studies in Chinese Linguistics, Volume 42, Number 1, 2021, 97-120 DOI: 10.2478/scl-2021-0003

(C) 2021 May L-Y Wong. Studies in Chinese Linguistics is published by Sciendo on behalf of T.T. Ng Chinese Language Research Centre, Institute of Chinese Studies, The Chinese University of Hong Kong. This work is licensed under the Creative Commons Attribution-NonCommercial-NoDerivatives 4.0 International License. 


\section{Introduction: The emergence of creative slang words in Hong Kong Cantonese}

This paper examines nine slang words $(\text { ciu4jyu } 5)^{1}$ that were created newly in Cantonese $^{2}$ and considers them as blends within the framework of conceptual integration theory (Fauconnier and Turner 2002; Brandt 2013). These slang expressions have been used widely by the youth and are gaining currency in the speech of the older generation. As with other coinages, they first appeared in discussion forums, teen magazines, comics, and online games which mostly appeal to the younger generation. As Grady et al. (1999: 111) put it, "[w]hat started out (undoubtedly) as some individual's creative, on-line, conceptual achievement has become a shared, entrenched conceptualization, presumably because the blend proved successful for some purpose, therefore arose again, and through repeated experience became conventional."

The past two decades or so have seen a rapid surge in publications on a range of slang words in Cantonese (see, for example, Ho 2005; Ah Foot 2008; Au Yeung 2008; Choi 2008; Chu 2008; Pang 2008; So 2008, So 2009; Tang 2009). Tang (2009: 13) has recorded over two hundred entries in his specialized corpus of Cantonese slang expressions, although some of them, as Tang (2009: 12) rightly points out, the slang expressions tend to be rather short-lived and used by only a tiny minority of young people. Most of these publications merely enumerate the slang expressions used by Hong Kong people and only few of them (e.g., Ho 2005; Au Yeung 2008; Tang 2009) examine these expressions from a linguistic perspective. Though these studies have offered insightful morphosyntactic and/or semantic/pragmatic accounts of Cantonese slang words, they do not explain the underlying cognitive mechanisms that are at the heart of the formation of these slang expressions.

The current study seeks to fill this gap by investigating the imaginative mental process that underlies the construction of these coinages. The whole process of creating nine slang words which have become common currency will be unveiled with the help of conceptual integration or blending theory, which is to be outlined in the following subsection. This study hopes to demonstrate that despite having wide applications in the English language, the blending theory can provide an integrated and coherent account of the cognitive mechanisms by which colloquial words are constructed and construed in terms of cultural experiences specific to a given non-Anglo locality.

1 Transcriptions of Cantonese in this paper follow the Jyutping romanization system formulated by the Linguistic Society of Hong Kong (1997).

2 Cantonese is the dominant language used in Hong Kong. The latest government survey shows that in 2016 Cantonese was the language spoken by $88.9 \%$ of the Hong Kong population. The other languages/dialects identified were Putonghua (Mandarin) (1.9\%), English (4.3\%), other languages (1.9\%), other Chinese dialects (3.1\%) (Census and Statistics Department 2017). 


\section{Background literature on conceptual integration theory}

One of the most striking aspects of conceptual integration is that it is conceived of as an "opportunistic", "on-line" process (Grady et al. 1999: 112; Coulson and Oakley 2005; Glebkin 2015; Eppe et al. 2018), which allows us to combine conceptual representations with astonishing speed, fluency, and freedom. Conceptual integration, or blending, is a theoretical framework for exploring conceptual structure in general, and the integration of information from disparate "mental spaces" in particular, that underlines the construction of meaning (Fauconnier and Turner 1998, Fauconnier and Turner 2002). Within the blending framework, mental images/representations activated at a particular moment are understood to be the contents of mental spaces, and each of the mental spaces has its own elements and relations (see Fauconnier 1994 for an introduction to mental space theory).

Fauconnier and Turner (2002) describe conceptual integration or blending as a dynamic process that occurs at the moment of perception to create new meanings from existing ways of thinking. Blending is a common cognitive activity, closely related to metaphor and analogy (Fauconnier 2001). Lakoff and Johnson (1999) define metaphor as constituting systematic mappings from a source to a target domain. For example, in I spent some time in France this year, money and time are the two domains that systematically map on to each other. The assumption of directionality from source to target is problematic, however. As Grady et al. (1999) point out, metaphor comprehension involves more than a set of directional mappings, and there is often an active combination and blending of information from target and source concepts. Despite the fact that conceptual blending also taps into the principle of mappings, it does so through the creation of input spaces and especially through the creation of a generic (third) space to engender a blend (a fourth space). Fauconnier (2001: 5) describes mental spaces as "small packets constructed as we think and talk, for purposes of local understanding and action. They are partial assemblies of elements, structures by frames and cognitive models". The central insight of conceptual blending theory is that two or more mental spaces can be linked via "mappings" (i.e., cross-space correspondences between counterpart elements and their relations) to yield novel inferences (Fauconnier 1997). In other words, mental spaces are based on more general and stable knowledge structures associated with a particular domain; they are temporary spaces used in the construction of meaning (Coulson and Oakley 2000). At its most abstract level, conceptual blending involves the projection of partial structure from two or more input spaces and the integration of this information in the blended space with emergent structure of its own.

Fauconnier and Turner's (2002) theoretical model is enriched with details on the governing principles and mechanisms of blending. Perhaps the most important theoretical construct established in blending that sets it apart from metaphor and analogy is that of emergent structure. "The blend develops emergent structure 
that is not in the inputs" (Fauconnier and Turner 2002: 42). There are three mechanisms for the development of emergent structure: composition, completion, and elaboration.

- Composition: "Blending can compose elements from the input spaces to provide relations that do not exist in the separate inputs."

- Completion: "We rarely realize the extent of background knowledge that we bring into a blend unconsciously. Blends recruit great ranges of such background meaning."

- Elaboration: "We elaborate blends by treating them as simulations and running them imaginatively according to the principles that have been established for the blend." (Fauconnier and Turner 2002: 48)

Since the blending theory was developed in the 1990s, many (cognitive) linguists have been infusing new insights into the theory. For instance, Coulson (2001) demonstrates how blending processes are widely utilized in all sorts of cognitive and linguistic phenomena. Presenting a new approach to the study of semantic change in historical linguistics, Grygiel (2004) argues that diachronic structures possess the same characteristics as their synchronic counterparts in that meaning alteration over time can be perceived as a by-product of conceptual blending processes. Grady (2005) sets out to clarify the role played by conventionalized metaphoric patterns in conceptual blending on which the theory has not taken a clear stand, and argues that these entrenched metaphoric expressions should not be thought of as the products of blending, but rather considered as basic, ready-made templates for the real-time construction of subsequent blends.

Creativity in word formation that manifested in noun-noun compounds has also been adequately explained in terms of conceptual blending by referring to the fact that the meaning of the compound is influenced by a metaphor-based semantic relationship between the two constituents rather than relying on the traditional, problematic structuralist notion of exocentricity (Benczes 2005, Benczes 2006, Benczes 2011). Other blending theorists extend the range of both theory and data by studying young children's plays (Sinha 2005), material artifacts (Hutchins 2005), fictional events in novels and movies (Rohrer 2005), mythology (Cánovas 2011), and the mathematical notion of infinity (Núñez 2005), to name but a few.

It would be instructional to point out some major contrasts between the Conceptual Metaphor Theory (CMT) and Conceptual Integration Theory before proceeding to the analysis of the Cantonese slang. First, not all blends are metaphorical. The prototypical metaphorical network which closely corresponds to the traditional CMT is the single-scope integration network where the commonality lies in frame-projection asymmetry. The source and target domains in CMT, which are construed as two separate inputs in the single-scope integration network, involve distinct frames. Only the frame of one of these inputs (the "source" in 
conceptual metaphor terms, the "frame input" in blending terms) is projected to the blend. Second, blending does not involve unidirectional cross-domain mappings whereas the mapping must go from the source domain to the target domain in CMT. Relatedly, blending also entails selective projection and backward projection that are lacking in CMT; there is selective projection of structure from inputs to the blended space and sometimes emergent structure from the blend can be projected back to the input spaces. Third, blending theory stresses the dynamic and mutable aspects of meaning of construction while CMT emphasizes the idea that there is underlying systematicity in the human conceptual system in which conceptual metaphors interact in order to provide relatively stable knowledge structure as manifested in the well-recognized and time-honored conceptual metaphors in everyday parlance such as LOVE IS A JOURNEY and TIME IS MONEY.

Please note that four different kinds of conceptual integration network lie at the heart of the blending theory (i.e., simplex, single-scope, double-scope and multiple-scope). In a simplex network, partial structure of a frame in one input is projected with its roles, and some elements are projected from the other input as values of those roles within the blend. In other words, the two input spaces are linked by a role-value outer-space vital relation while in each of these spaces there is an inner-space cause-effect link. In this type of integration network, the blend integrates the frame and the values in the simplest way (hence the name "simplex").

Fauconnier and Turner define a single-scope network as an integration network that "has two input spaces with different organising frames, one of which is projected to organise the blend" (Fauconnier and Turner 2002: 126). They also note that single-scope networks are prototypical of "source-target metaphors" (Fauconnier and Turner 2002: 127) that are at the heart of CMT (see, for example, Lakoff and Johnson 1980): the source domain in the CMT tradition corresponds to the framing input in blending theory (i.e., the input that provides the organizing frame to the blend), whereas the target domain corresponds to the focus input (i.e., the input that is the focus of understanding).

While a double-scope network has two inputs with different organizing frames as well as a blend that incorporates partial structure of each of those frames as its organizing frame and has its own emergent structure (Fauconnier and Turner 2002: 131); a multiple-scope network is a more elaborate kind of conceptual integration, in which several inputs are projected in parallel for blending (Fauconnier and Turner 2002: 279).

The present study seeks to provide support for addressing the culturalhistorical peculiarities of cognitive mechanisms by referring to the unique cultural experience in the explanation of the cognitive operations underlying the creation of certain slang words. In the remainder of the paper, nine slang words from Hong Kong Cantonese will be analyzed in terms of these different types of conceptual integration network in Sections 3 and 4 with an aim to shed light on the highly creative process of word formation rooted in these metaphorical expressions 
that reflect changes in cultural conceptualizations concerned to emotions, bodily reactions, and social relationships among local speakers.

\section{Conceptual blending of slang words involving emotions}

Of the nine Cantonese slang expressions being studied, O嘴 (oulzeoi2; literally meaning 'with one's mouth wide open'), 滴汗 (dik6hon6; literally meaning 'to sweat'), and 啞晒 (aa2saai3; literally meaning 'to be mute') generally refer to more or less the same mixture of emotional states such as shock, bewilderment, and embarrassment, although these three slang words each describe a somewhat different bodily reaction. ${ }^{3}$ In fact, the correlation between emotions and bodily reaction states has been conceived of as real and well experienced ever since the impressive analysis of Lakoff and Kövecses (1987) on the conceptualization of anger. In their analysis, they reveal a metaphoric mapping between heat and anger in conventional expressions: You make my blood boil. He's just letting off steam. When I told him, he blew up. (Lakoff and Kövecses 1987: 195). They also note that this metaphor is based on the physiological effects of anger in the human body: increased body heat, blood pressure and redness of face, as in the following expressions: He lost his cool. I almost burst a blood vessel. He was red with anger. (Lakoff and Kövecses 1987: 195).

Following on this idealized cognitive model of anger, Fauconnier and Turner (2002: 300) propose a conventional cultural notion of this cause-effect vital relation linking emotions to their physiological effects in what they refer to as "The Story of Emotion and Body". This frame prototypically applies to all animate beings, including humans. Essentially, it has a role for emotion and a role for bodily state, along with the inner-space frame relation (cause-effect) of the emotion to the bodily state. Suppose an integration network has one space containing only this frame, and another space containing a specific bundle of emotions and a specific bodily reaction. This is what Fauconnier and Turner (2002: 120-122) call "a simplex network", and this integration network is crucial to our understanding of these three Cantonese slang words.

All of these expressions exhibit the cognitive operation involving the roles of schematic emotion and schematic bodily state where the role emotion connects to the value which is a bundle of emotions such as shock, bewilderment or embarrassment, and the role bodily state connects to one of the following values mentioned: mouth being wide open (as in O觜 oulzeoi2); sweating (as in 滴汗 dik6hon6); being mute (as in 啞晒 aa2saai3). As with other simplex networks, the blended space in the integration network is compositional in the sense that the entirety of the relevant information from both inputs is brought into the blend.

3 So $(2008: 6,58)$ notes that both O嘴 oulzeoi2 and 滴汗 dik6hon6 are thought to be originated from Japanese comics and subsequently represented as emoticons (-o-) and ( =.=") commonly used with early stage computer-mediated communication tools such as ICQ and MSN messenger. 
The diagram in Figure 1 shows the cross-space mappings between the two input spaces. Here, one input contains a frame with roles but no values, the other input contains unframed elements, and the inputs are matched by a frame-to-values connection. As observed in the figure, the emotional and bodily states are fused in the blend as emergent structure that is embodied in the interchangeability of the slang words: the bodily state denoted in each of the slang words is no longer a salient feature in the expression but rather the emotional state of confusion and shock and that is what the slang words actually mean.

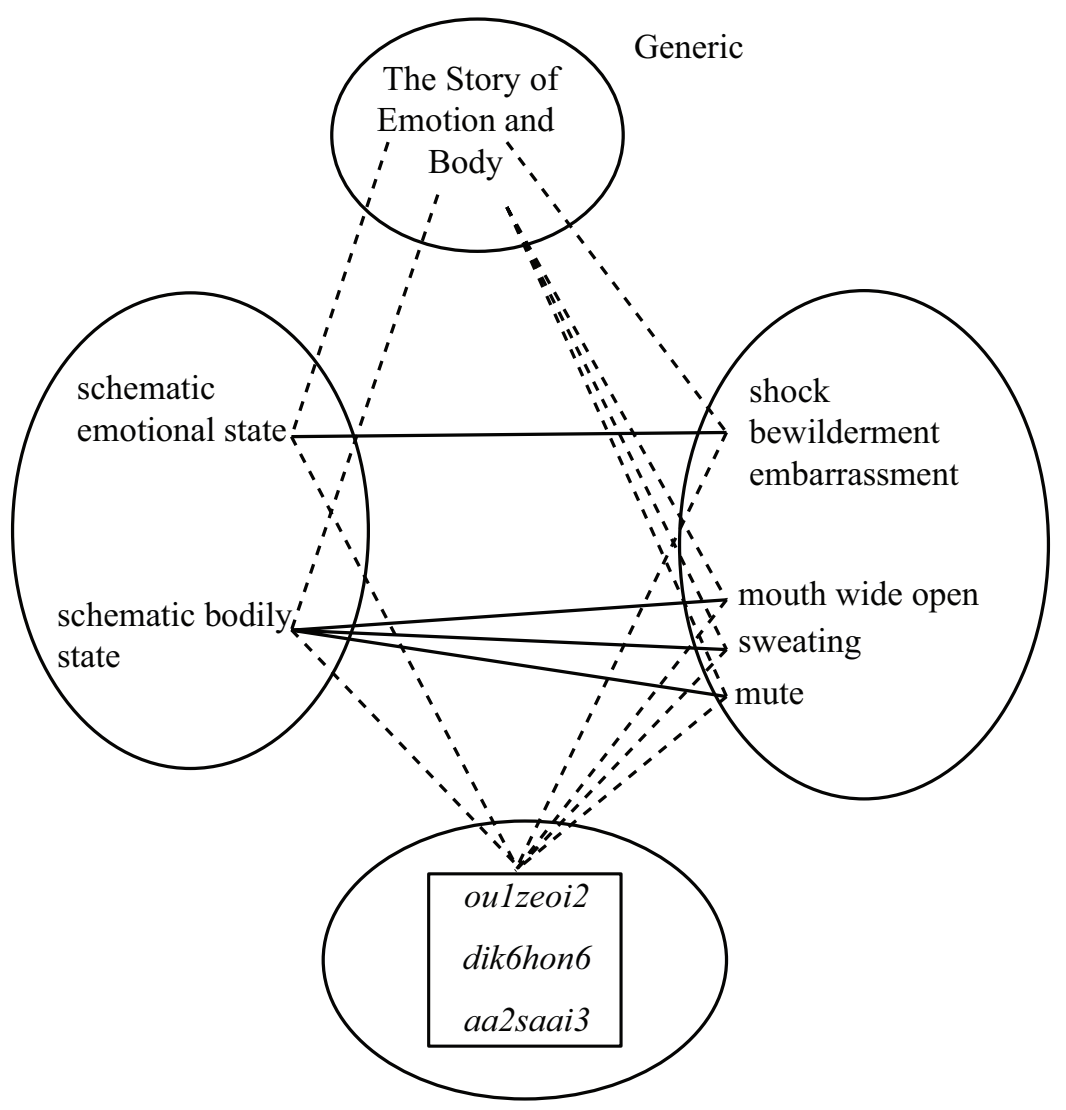

Figure 1 Conceptual integration network for oulzeoi2, dik6hon6, and aa 2 saai $3^{4}$

4 In keeping with the notation developed by Fauconnier and Turner (2002: 45), the circles represent mental spaces, the solid lines indicate the cross-space mapping between the inputs, the dotted lines indicate outer-space connections between inputs and either generic or blended spaces, and the solid square in the blended space represents emergent structure. 


\section{Conceptual blending of slang words involving social relationships}

\subsection{Single-scope network}

Three of the Cantonese slang expressions under investigation in this study (i.e., 潛水 cim4seoi2, 屈機 watlgeil, 窒機 zat6geil) are examples of singlescope networks.

The slang word 屈機 watlgeil 'to trump' originates from computer jargon to describe a situation in which a player of a computer game is invincible, having superior skills and taking advantage of loopholes inherent in certain parts of the game. The specialized use of this word in computer games has now set foot or landed in ordinary real-life situations where two people are in a competition of some sort and one of the two has a much higher caliber and thus stands a much higher chance to win. This term is typically used by the loser of the competition to show his/her discontent and anger over the defeat. It can sometimes be used in non-contesting circumstances which are considered as unfair and unreasonable that one finds it difficult to succeed despite one's great efforts. So (2008: illustration 1.13) gives an example in which this word is used where two basketball teams are in competition, while one of which has players as tall as Yao Ming (a professional Chinese basketball player who plays for the Houston Rockets of the National Basketball Association [NBA] and is currently the tallest player in the NBA).

The scenario of two virtual players fighting in a computer game gives us a vibrant, compact frame to use in compressing our understanding of two basketball teams in competition. In terms of ability, one of the two teams with very tall basketball players definitely has the edge over the other. This construal of the situation builds up a conceptual integration network. There is a cross-space mapping between the fighting input and the sports input that maps, for example, each fighter to a basketball team, a punch to an attack, and a blow to an effective action to score points. In short, the blend has inherited both the organizing frame and frame-typology from one of the inputs (fighting) but not the other (see Figure 2). Nevertheless, the blend is still distinct from the framing input. The blend has the essential new structure: the feelings of discontent and anger on the part of the losing team. This new meaning leads to the creation of the Cantonese slang word watlgeil. Referring back to the example above, given that one of the basketball teams has very tall (and probably more talented) athletes, it has higher chance or probability to win the game. This "running of the blend" gives rise to inferences that can be projected back to the sports input, yielding the all-important interpretation that after being crashed out of the game, the players of the losing team feel extremely upset, discontented and angry over the fact that the odds are stacked against them succeeding in the competition right from the outset with such a strong opponent.

We can see that in this case (and the other two cases to be discussed further in the following paragraphs) the framing input imposes its structure in the blended 
space. By means of filling out, or instantiating, the roles in the framing input by elements in the focus input, we get a blend that is largely structured by the organizing frame of one input but has emergent meaning of its own which is not recruited from the framing input.

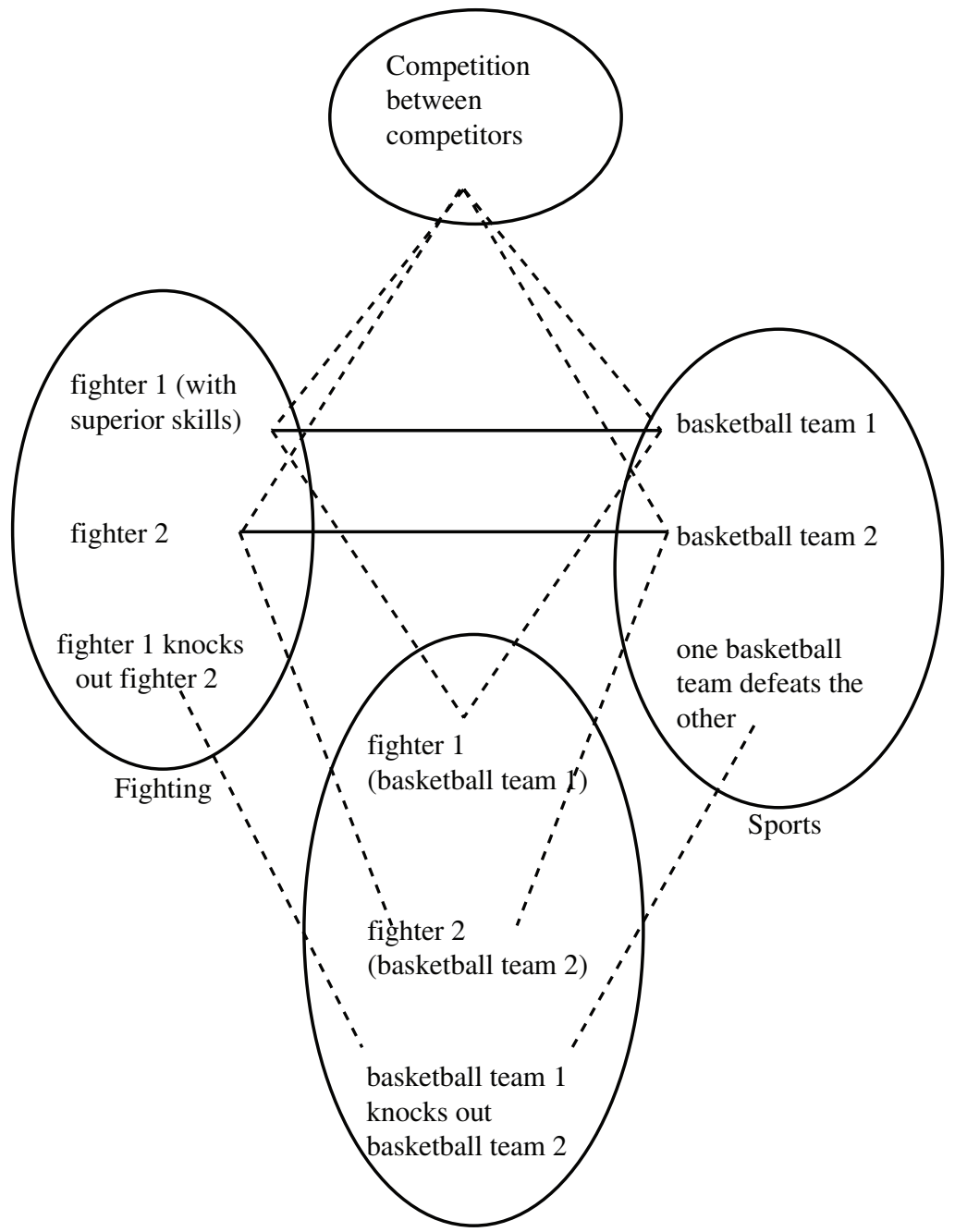

running the blend:

basketball team 2 loses the game to basketball team 1 with very tall players ( $\rightarrow$ inferences about the feelings of the losing team)

Figure 2 Conceptual integration network for watlgeil 
Now consider the slang word 潛水 cim4seoi2 ('go into hiding'; literally meaning 'go diving'). Suppose a man has not been in touch with his friends for a long time. The frame that is exploited in the blend for purposes of understanding is the frame of one input (underwater diving), and the point of the blend is to cast light on the other input (the man's being in hiding). There is systematic cross-space mapping between the two input spaces. For instance, a diver is mapped onto a troubled adult; the action of diving is mapped onto the deliberate action of avoiding contact with people; and the underwater environment is mapped onto the solitary life a man has chosen to live.

What is significant in this integration network is that the framing space (diving) has preexisting compressions that are exploited to induce similar compressions for the focus input (hiding). In the framing input, diving already constitutes an integration of several different events (traveling to the dive location, wearing diving outfits, carrying breathing equipment, swimming under water, discovering the amazing and hidden underwater world, watching incredibly colored sea creatures, having fun, finishing the dive, going out of the water, and getting back to the ship). But its counterpart in the focus input, if considered independent of the network, is a series of diffuse events. The adult has had a troubled life on and off. The deliberate action of going into hiding may occur over a long period of time, involve many causes, and take place in many physical locations. The integrity in the framing input is projected to the blend so that this array of discrete events in the focus input acquires, in the blend, a conceptual integration of its events into a unit.

Yet another slang word that is based on a single-scope network is 窒機 zat6geil. Literally, this word means that a machine, typically a computer, suffers from intermittent failure and it is now commonly referred as someone similar to a person who stutters. This slang expression can be thought of as a case of blending in the following way. There are two input spaces (machine malfunction and stutter), a generic space and a blended space. There are systematic correspondences between the elements of the framing input (machine malfunction) and those of the focus input (stutter).

- machine/computer $\rightarrow$ stutter

- problems with operating smoothly $\rightarrow$ problems with speaking fluently

- stopping and starting repeatedly $\rightarrow$ pausing and repeating sounds

Since both machine malfunctioning and stuttering are forms of failure at doing something that a machine or individual is expected to do, the generic space contains the skeletal information "failure to work properly". In the blend, we have the frame of malfunctioning in which a stutter fails to speak or say something correctly and has to stop and start repeatedly. We therefore get a blend that is both old and new with respect to the inputs. Its newness derives from the fact that the stuttering individual in the focus input is now considered as participating metaphorically in the "old" malfunctioning frame just like a machine. Again, this is a general 
phenomenon in the case of single-scope integration networks and an additional way of producing novel figurative thought. ${ }^{5}$

\subsection{Double-scope network}

The Cantonese slang word 交波 gaaulbol (literally meaning 'to pass the ball'; now meaning 'to shirk responsibilities') is a double-scope network. The two principal inputs have different organizing frames: the frame of football, on one hand, and the frame of office work on the other hand. The frame in the blend draws from the frame of football - playing in a football team, moving a ball along the pitch, kicking the ball into the other team's goal - as well as from the frame of office work - people holding on a job position with specific duties attached to it, sharing the workload, etc.

At first glance, this slang expression looks like a straightforward single-scope network where the organizing frame of team work and goal-scoring in a football match could be projected to organize the blend - a blend in which someone shirks his/her responsibilities or duties especially those that are difficult or unpleasant. Football players belonging to the same sports team can be mapped onto people working for the same organization; scoring a goal can be mapped onto finishing a task; a football pitch can be mapped onto an office space; the football can be mapped onto the task at hand; and so on and so forth.

A closer look, however, reveals that this cannot be a single-scope network as the cross-input mapping aligns the typologies of the inputs in a single-scope network and that typology appears in the blend. But in the Cantonese slang word gaaulbol, the typologies of the inputs clash on causality, intentionality, and internal event structure. In all these cases, the blend takes its typology from the office input, not from the football input.

The causal structure in the blend comes from the office input, not from the football input. Shirking responsibilities causes delay in completing the work, but passing the ball from one player to another leads to progress toward goal. Even if a footballer is atypically fearful of losing the ball on his/her part and intentionally passes it to other players as soon as possible to minimize the risk, there is still not the slightest causal connection between the passing and the delaying.

The intentional structure comes from the office input, not from the football input. In the face of a difficult task, the manager avoids responsibilities with intent

5 Note that the verb stutter in English also has both of the meanings expressed by the Cantonese slang word zat6geil (see, for example, Cambridge Dictionary Online and Macmillan Dictionary Online). However, it seems that the basic and metaphorical meanings are different in the two languages. It is generally considered in English that the "speak" sense of the verb stutter is the basic meaning and the "operate" sense of the verb is the metaphorical meaning: in both the Cambridge and Macmillan dictionaries, the "speak" sense comes before the "operate" sense under the entry stutter. In Cantonese dictionaries, however, it is in reverse that appears to be true. 
to avoid failure on their part; if they did not get involved in the task, they would (or could) be not blamed for its failure. In contrast, passing the ball to another player in a football match is conceived of as a constructive course of action toward success. In other words, while the manager intends to play a minimal role in the completion of the unpleasant task, the footballer intends to make central contribution to the success of the game.

The internal event structure comes from the office input. In that input, it might be true that the greater responsibilities you are faced with, the more likely you avoid taking them on. But in the football input, there is no correlation between the stakes of a particular football match and chances of a footballer passing the ball.

The blend in the Cantonese slang word gaaulbol inherits football players who are all dribbling the ball and passing the ball from the football input. But it inherits causal, intentional and internal event structure from the office input. The two inputs are not simply juxtaposed. Rather, emergent structure specific to the blend is created, with all the curious characteristics noted above. The existence of a daunting task causes someone to shirk duties and is a necessary precondition for it. It follows straightforwardly, at least in the blend, that the greater the responsibilities, the greater the risk of failure, and the greater the chance for the person in charge to avoid taking part. In the blend, it becomes possible for everyone to be aware of someone's irresponsible act and to be critical of that person - a judgment that will project back to the office input to produce suitable inferences (i.e., to highlight misconduct and a sense of betrayal). Figure 3 shows the blending of gaaulbol.

Another Cantonese slang expression, 打邊爐 daa2bin1lou4 ('to smoke outdoors, typically surrounding a trash can'; literally meaning 'to have a hot pot meal' $)^{6}$ is also a double-scope network. On January 1, 2007, the Hong Kong government imposed a smoking ban on most indoor public places while some 800 bars, saunas, nightclubs, and mahjong parlors granted exemptions till mid-2009. At present, with the smoking ban in full force, it is against the law for anyone to light up in all indoor areas. People are now forced to the streets, gathering and smoking near trash bins. The regulars at times share small talks just like friends at a hot pot dinner and gradually form a new community known as "Hot Pot Pack"7 and Cantonese slang daa2bin1lou4 was coined under these circumstances.

6 Hot pot meals are often eaten in the winter in many East Asian countries (e.g. Japan, Korea and China). A hot pot meal is served with a wide variety of ingredients including thinly sliced meat, meat balls, leafy vegetables, bean curd, dumplings, and seafood. These ingredients are cooked by diners themselves, who put them into a simmering metal pot placed at the centre of the dining table. As with many other food traditions, there are wide-ranging regional variations of hot pot meal (see Zhongli 2007: 62-67 for a description).

7 The term "Hot Pot Pack" first appeared in the movie release of a Hong Kong romance comedy Love in a Puff. See the full text at http:/www.thinkasiathinkhk.com/uk/en/filmweek.htm (accessed 22 April 2021). 


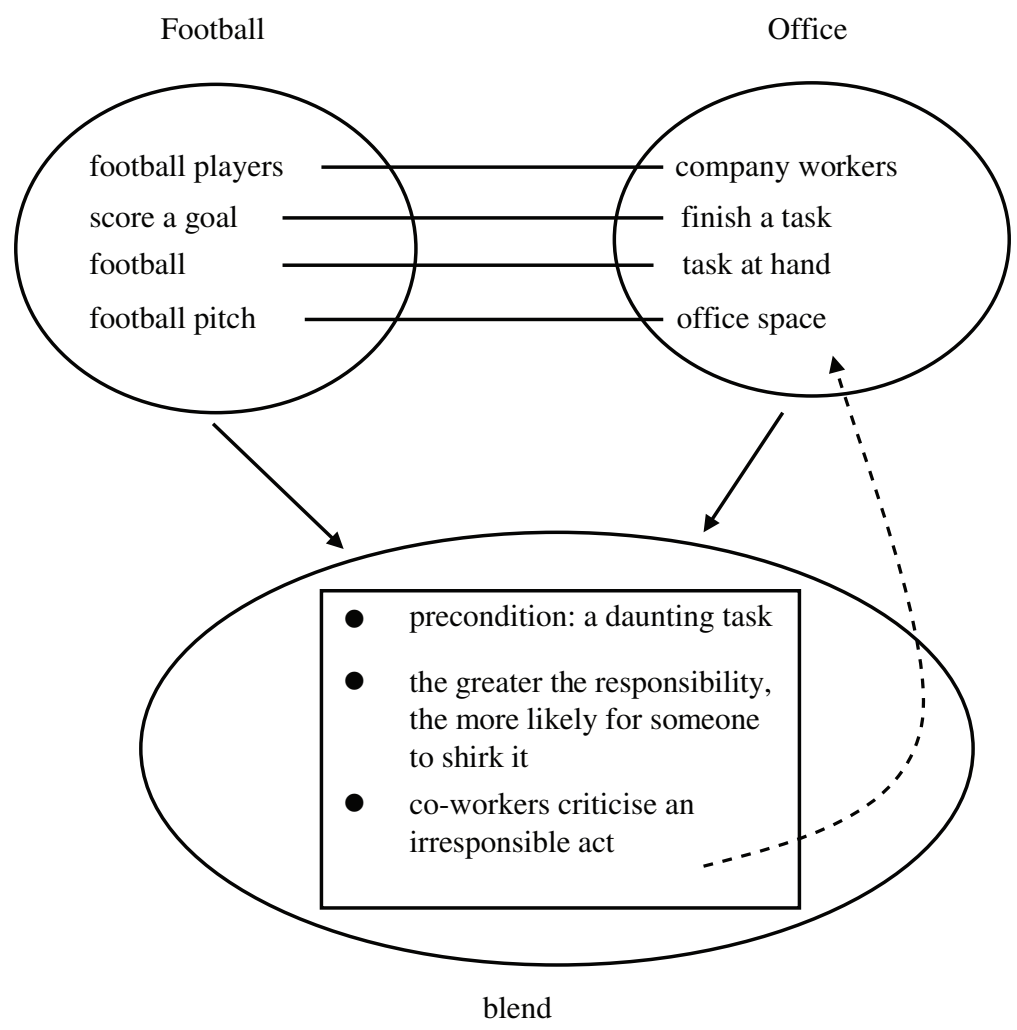

Figure 3 Conceptual integration network for gaaulbol

The blend has two input spaces - one with hot pot and the other with smoking. There is a partial cross-space mapping between these inputs: the trash can is the counterpart of the metal pot, and the smoke is the counterpart of the steam. This blend is double-scope because while it takes much of its organizing structure from the hot pot input space - it has a group of people gathering around a table eating food cooked in a metal pot and it now takes crucial event shape structure from the smoking scenario: with the smoking ban in place, Hong Kong citizens are no longer able to light a cigarette in all indoor public places such as restaurants, cinemas, and shopping arcades. They have no choice but to smoke outdoors. To avoid walking a long distance to dispose of a cigarette butt, many people prefer smoking near a trash can. Thus the trash can on the corner of the street has become a popular smoking spot, frequented by people from all walks of life standing in a huddle to light cigarettes.

The hot pot space supplies to the blend a tight compression of time with a human scale: a person goes outside and takes a puff on a cigarette and shortly afterward another person follows suit. In reality, it would be hard to predict how 
many smokers would be puffing away at a single point of time in a particular location. It might take a long time to have a group of five to six people smoking round a street trash can. However, the apparently lengthy waiting time is remarkably shortened and compressed into a single moment at which smokers at a particular location all light up simultaneously, in keeping with what normally happens in the hot pot space - every person is busy cooking their favorite food when the hot pot is simmering.

There is a generic space whose structure is taken when applying to both inputs: one group of people is involved in an activity motivated by some purpose. In the generic space, the nature of the activity is not specified.

What is striking about this Cantonese slang word is the fact that it is a counterfactual blend. As Fauconnier and Turner (2002: 230) note, counterfactuality does not necessarily refer to "forced incompatibility" between reality and unreality, although it is widely accepted that counterfactual spaces are spaces that do not refer to reality. Rather, they suggest that a space is counterfactual depending on the viewpoint one takes - that is, on the space that one takes to be "actual". It is this narrower and more useful sense of the term "counterfactual" that is being adopted in the analysis of the Cantonese slang word daa2bin1lou4. While the smoking scenario depicted in the blend clearly involves a joint activity (i.e., people gather round a street trash can to smoke), it is counterfactual to the smoking input space in which the prototypical mental image of smoking is a sole activity (i.e., an individual puffs on a cigarette, pondering and enjoying a moment of privacy). The blended space is also counterfactual to the hot pot input in that while people smoking at a trash can on the street are not normally acquainted, people who eat together in a hot pot meal are certainly friends, family members, co-workers, and the like.

Another striking feature of this blend consists in the power of blending that it exhibits. Always there are many different possible directions in which we can run a blend. For example, a male smoker and a female smoker, who do not know each other, might meet regularly at a trash bin and have a small talk. That particular elaboration would lead to something interesting such as a love story, as described in a recent Hong Kong movie Love in a Puff. ${ }^{8}$

\subsection{Multiple scope-network}

Until now, we have used a minimal template of conceptual integration that involves four spaces: two input spaces, a generic space, and a blended space, we will now turn to an example from So (2008: illustration 2.26) about the

8 The romance comedy was directed by Pang Ho-cheung and was listed as one of the best ten China films of 2010 (Zhou 2010). The film revolves round a love affair between Cherie (played by Miriam Yeung) and Jimmy (played by Shawn Yue) both of whom worked in neighboring buildings and gathered for cigarette breaks during office hours at trash bins near their work premises. Cherie started flirting with Jimmy and eventually they took a fancy to each other. 
Cantonese slang word 集郵 zaap6jau4 (literally meaning 'to collect stamps'; now meaning 'to have a lot of different sexual partners or sexual relationships') where a complex network of input spaces has to be employed to explain its meaning construction.

The multiple-scope blending of the slang word can be illustrated in the following example.

(1)

\begin{tabular}{|c|c|c|c|}
\hline $\begin{array}{l}\text { 集郵 } \\
\text { Zaap6jau4 } \\
\text { collect. Stamps }\end{array}$ & $\begin{array}{l}\text { 係 } \\
\text { hai6 } \\
\text { is }\end{array}$ & $\begin{array}{l}\text { 不良 } \\
\text { bat1loeng4 } \\
\text { malicious }\end{array}$ & $\begin{array}{l}\text { 啫好, } \\
\text { si3hou3, } \\
\text { hobby }\end{array}$ \\
\hline $\begin{array}{ll}\text { 你 } & \text { 小心 } \\
\text { lei5 } & \text { siu2sam1 } \\
\text { you } & \text { careful }\end{array}$ & $\begin{array}{l}\text { 集 } \\
\text { zaap6 } \\
\text { collect }\end{array}$ & $\begin{array}{l}\text { 上瘊。 } \\
\text { soen55jan5. } \\
\text { get.addicted }\end{array}$ & \\
\hline
\end{tabular}

In this example, we find two blending networks, where input spaces of each network are connected by a metaphoric mapping. In the first network, one input space is a promiscuous lifestyle. It has a womanizer and his sexual partners as its major participants. The other input space gets its structure from the hobby of stamp collecting. The stamp collector is the counterpart in this cross-space mapping of the promiscuous individual, and the postage stamps are the counterparts of the sexual partners. The second blending network also has the input space of the promiscuous lifestyle. Its other input has one kind of addiction, that of sex. In the blended space, the womanizer is a sex addict and his sexual partners are relegated to be objects of addiction.

While these two metaphoric integration networks share an input space - the promiscuous lifestyle, the other two input spaces (philately and addiction) are linked via an outer-space vital relation of Change. When a stamp collector cannot stop the activity of collecting stamps, the entire nature of doing it for pleasure is totally ruined and the hobby itself becomes highly addictive. Under these circumstances, this outer-space Change link aligns stamp collectors to addicts and stamps as objects of addiction. In the blend, where the force of excessive/obsessive relation is projected from the addiction space, the collectors/stamps structure serves to add useful features and subtract others. For instance, the stamp collectors are so keen to collect stamps from different countries, and thus in the blend there is an element of diversity just as there is a series of temporary sexual relationships with different women, and the "stamps" are never part of the preoccupations of a womanizer. In the addiction space, on the other hand, there is an inherent property of dull uniformity.

In fact, the linguistic form employed in the example is the characteristic of multiple-scope blending. Here, we find vocabulary for the three inputs in a single sentence. The first part of the sentence (before the comma) is a prompt to begin to 
build an integration network whose inputs are the spaces of hobby and promiscuity. When we learn almost instantly that having different sexual partners is something of a destructive hobby, we include that judgment in the blend, but its relation to the other elements is in many ways indeterminate until the third space of addiction is offered to us. Then one way of accounting for the destruction is clear: there is another space, with an addictive personality that has a metaphoric cross-spacing mapping to the space of promiscuity and an outer-space vital-relation connection of change to the space of hobby. A multiple blend is now off and running. The addiction space is now also an input to the blend, in which we have womanizers/ stamp-collectors/sex addicts indulging in women/stamps/sex.

With three mutually connected spaces for stamp collecting, addiction and promiscuity, the counterpart structure is as follows.

$\begin{array}{lll}\text { STAMP COLLECTING } & \text { ADDICTION } & \text { PROMISCUITY } \\ \text { stamp collectors } & \text { sex addicts } & \text { womanizers } \\ \text { stamps } & \text { sex } & \text { sexual partners }\end{array}$

All three spaces are selectively projected to a blended space in which event participants inherit features of all three inputs. One group is construed as an object: they are stamps; sexual activities; and they are sexual partners. The other group consists of collectors/addicts/womanizers playing the role of exploiters.

Call the blend B and the three input spaces S, A, and P (stamp collecting, addiction and promiscuity, respectively). In the ultimate network configuration, shown in Figure 4, because there are cross-space mappings between the three inputs (indicated by solid lines), we can have up to three distinct generic spaces. Informally, the schematic structure of $\mathrm{G}_{\mathrm{AP}}$ common to $\mathrm{A}$ and $\mathrm{P}$ is an obsession schema. $G_{S P}$, common to $S$ and $P$, is a diversity schema. The generic space $G_{S A}$ brings out the essence of uniformity in both $\mathrm{S}$ and $\mathrm{A}$. The two generic spaces $\mathrm{G}_{\mathrm{AP}}$ and $\mathrm{G}_{\mathrm{SP}}$, though distinct, can be seen as subcases of an even more schematic generic $\mathrm{G}$ of the form "strong desire". Because it fits A and P on one hand and S and P on the other hand, and $\mathrm{G}$ automatically fits $\mathrm{A}$ and $\mathrm{S}$.

There are different vital relations between the inputs S, A, and P. As noted earlier, Change links $\mathrm{S}$ to A because a keen interest in collecting stamps may turn into an addiction when the strong desire becomes uncontrollable. The vital relations between all three inputs include identity, intentionality, and time connectors. The collector/addict/womanizer remains the identical person: the counterparts (stamp collectors, sex addict, and promiscuous individuals) in S, A, and P are projected to the blend and fused there, and that vital relation of identity is compressed into uniqueness in the blend. Intentionality links the three inputs in that the three types of people all intend to do something: the stamp collectors intend to collect stamps; the sex addicts intend to have sex; and the womanizers intend to pick up different women. Additionally, time links the three input spaces because the hobby/ addiction/lifestyle obviously persists for a considerable period of time. 


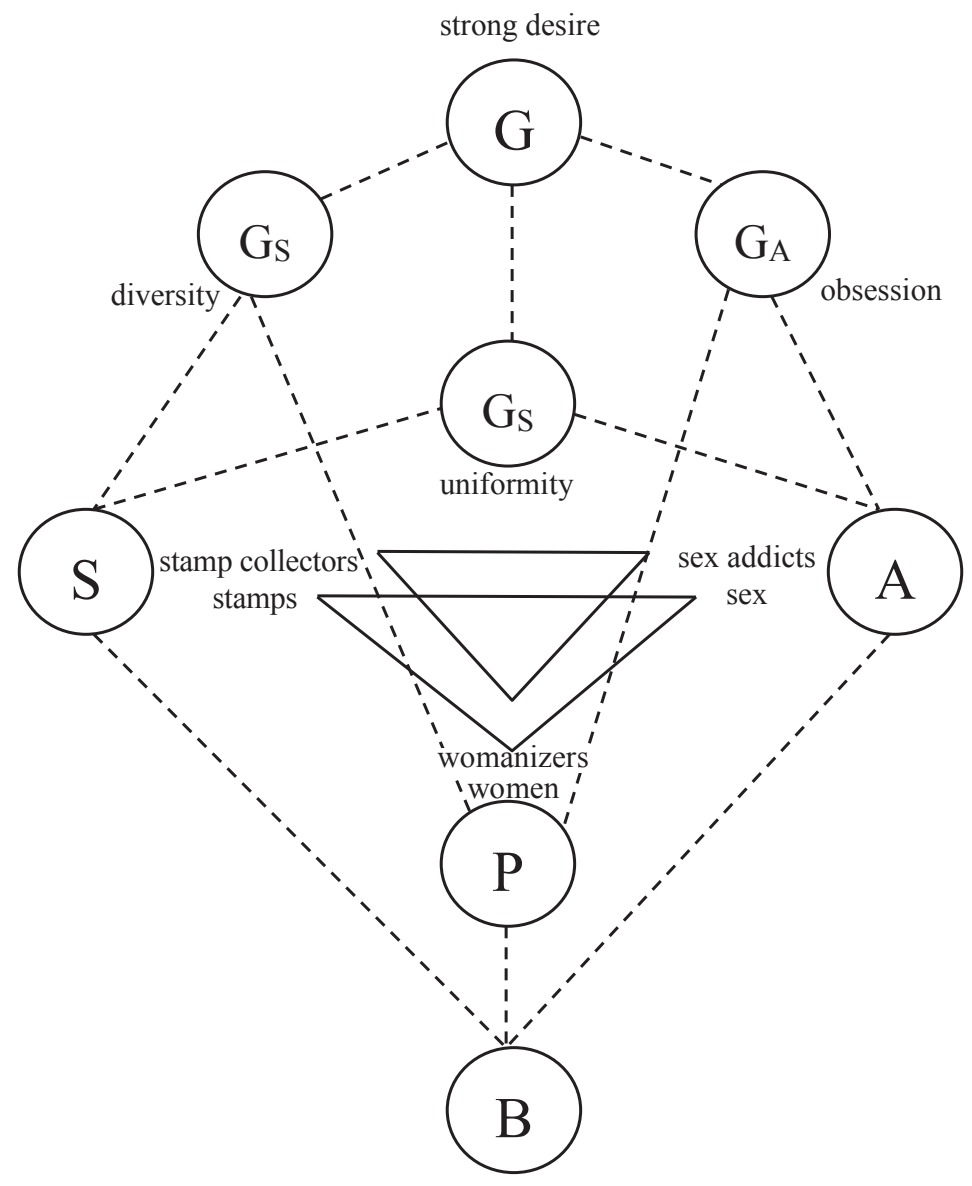

Figure 4 Conceptual integration network for zaap6jau4

\section{Conclusion}

As demonstrated in the preceding sections, semantic change can be understood as conventionalization of context-dependent modification of usage. Such kind of on-line meaning construction is aided by the dynamic operation of blending processes that unfold in the conceptual integration network. In simplex networks, we identify a particular entity with a slot in a more general conceptual frame. For instance, the understanding of $\mathrm{O}$ 觜 oulzeoi2, 滴汗 dik6hon6, and 啞晒 aa2saai3 depends on the conceptual operation in which a particular physiological effect of our body is correlated with our cultural model of emotions in the Story of Emotion and Body. Our bodily and emotional states and the Story of Emotion and Body Frame represent the input spaces for the conceptual integration. In the blend, a specific bodily reaction and its associated emotional state are fused; any 
reference to the bodily state should suffice to trigger the mental representation of associated emotions. This is an emergent property of the blend as the inner-space cause-effect connection (i.e., the mention of a bodily reaction triggers the mental experience of a particular set of emotions) in the blend is exactly the reverse of that of the input spaces where emotions are the cause, rather than the effect, of bodily reactions.

The blending of the three Cantonese slang words 潛水 cim4seoi2, 屈機 watlgeil, and 窒機 zat6geil involves the use of single-scope networks. In these integration networks, one of the input spaces provides frame structure to organize the blend. The understanding of these three slang words is therefore aided by this framing input - someone's going into hiding (cim4seoi2) can be understood as going diving in deep waters; someone stuttering (zat6geil) is well captured by a mental representation of a computer suffering from intermittent failure; someone's competing in a tough situation and having a very slim chance of winning (watlgeil) can be understood in terms of a similar scenario between two virtual fighters in a computer game.

More complex conceptual integration networks are required for understanding 交波 gaau1bo1, 打邊爐 daa2bin1lou4, and 集郵 zaap6jau4. In the case of 交 波 gaaulbol, the frame of football and the frame of office work both contribute to organize the blend in which someone shirks his/her responsibilities or duties. While there is partial cross-space mapping that can be established between the two inputs (e.g., footballers vs. workers; scoring a goal vs. finishing a piece of work, etc.), the crucial frame elements and relations such as causality, intentionality, and internal event structure are inherited from the office input only. The blend for 打邊 爐 daa2bin1lou4 is also double-scope. Much of the frame structure of the blend comes from the hot pot input but important event shape structure is taken from the smoking input. There is compression of time in the blend - the separate moments at which different people go outside and take a puff on their cigarettes at different locations are now compressed into a single moment at which people are smoking simultaneously at a particular trash can.

The Cantonese word 集郵 zaap6jau4 prompts for a multiple-scope network in which three input spaces (i.e., stamp collecting, sex addiction, and promiscuous lifestyle) are projected in parallel for blending. Two kinds of crossspace mappings contribute to this complex integration network. The first kind consists of a metaphoric mapping - promiscuity as addiction. The second kind consists of a vital-relation connection of change, linking philately to addiction. Similar to a stamp collector who is interested in collecting stamps belonging to different countries, a promiscuous individual has a lot of different sexual partners. Just as a sex addict cannot control his/her sex drive, so a womanizer cannot refrain from having temporary sexual relationships with women. The three input spaces are further connected by identity, intentionality, and time, and give rise to three distinct generic spaces which evoke different schemas (i.e. obsession, diversity, 
and uniformity) that form the basis of an even more schematic generic space, that of "strong desire".

It is hoped that this paper could lend credence to the statement advanced by Fauconnier and Turner (2002: 49) about the power of blending.

The creative possibilities of blending stem from the open-ended nature of completion and elaboration. They recruit and develop new structure for the blend in ways that are principled but effectively unlimited. Blending operates over the entire richness of our physical and mental worlds. (Fauconnier and Turner 2002:49)

In the conceptual integration networks discussed in this study, we have seen how elements and relations from familiar conceptualizations can be combined into new and meaningful ones. These emergent meanings of the Cantonese slang expressions can then be fully explained which would have remained a mystery in the literature, were it not for the power of blending. Through running the blend, the feelings of discontent and anger on the part of the loser (as in the case of watlgeil) can be projected to the input space of fierce competition with an invincible competitor; the criticisms made by co-workers about someone shirking responsibilities can be projected back to the office input (as in the case of gaaulbol). All these new meanings have been brought to the forefront of our attention by elaborating the "slang" blends imaginatively according to the principles that have been established in the blends. The examples illustrate that new meanings are created in an on-line construction process nicely captured by conceptual blending and we are able to envisage our occasion-bound experience in wellknown and familiar material. We have also seen that the emergent meanings are always context-dependent and triggered in the mind of the individual speaker in an effort to adapt the language to new circumstances through transformations of familiar expressions. This lends credence to Glebkin's suggestion that the primary function of conceptual blending, "at least in the majority of paradigmatic cases, is to adapt existing knowledge to the needs of lay people" (2015: 104). However, as Fauconnier and Turner (2002) point out, there are unlimited ways in which we adapt conceptual structure. Our discussion of the new coinage daa2bin1lou4 is a case toward that point; the formation of the word might have made use of the operation of conceptual blending as its basic instrument of imaginative invention on the basis of an existing word. Hopefully, the current study has demonstrated that though integration networks are uniform in their dynamics, integration networks can serve different goals and address a whole range of contextdependent issues that would have been impossible with other theories - at least in the study of slang. Blending is a ubiquitous, fundamental cognitive activity with wide applications. Despite investigating a relatively smaller range of examples from the very rich slang terms used in Hong Kong Cantonese, this research has echoed Fauconnier and Turner's view that cultural peculiarities prompt blends in an ingenious manner. The comprehension of a slang word must be understood in 
terms of both the cognitive processes of meaning construction at work and the unique culture of a locality.

\section{Acknowledgments}

The author would like to thank two anonymous reviewers for their critical and constructive comments on an earlier draft of this article. I am extremely grateful to Mian and Eppie at the Editorial Office for their professional and stellar assistance in bringing the publication of this manuscript into fruition. Special thanks go to the audience at the second international Chinese Language and Discourse symposium (9-11 of June 2012) held at the Nanyang Technological University, Singapore, for their useful feedback on a preliminary study of the current research into Cantonese slang. The keen interest in applying cognitive linguistics to analyzing Cantonese has been developed out of previous research into verb-preposition constructions in Hong Kong English from the theoretical framework of Cognitive Grammar (Linguistics 52:3), as well as an exploratory study of a new analytical approach to examining visual imagery in relation to the underlying cognitive processes involved, connecting cognitive and social semiotic perspectives (Cognitive Semantics 4:1). The usual disclaimer applies.

\section{References}

Ah Foot. 2008. Wangluo chaoyu zidian 08 [A dictionary of internet trendy expressions 2008]. Hong Kong: Pi Publication Ltd.

$\mathrm{Au}$ Yeung, Ben. 2008. Yuejiang Yuefa [Cantonese and its very own grammar]. Hong Kong: Ming Cheong Press.

Benczes, Réka. 2005. Creative noun-noun compounds. Annual Review of Cognitive Linguistics 3(1). 250-268.

Benczes, Réka. 2006. Creative compounding in English: The semantics of metaphorical and metonymical noun-noun combinations. Amsterdam \& Philadelphia: John Benjamins.

Benczes, Réka. 2011. Blending and creativity in metaphorical compounds: A diachronic investigation. In Sandra Handl \& Hans-Jörg Schmidt (eds.), Windows to the mind: Metaphor, metonymy and conceptual blending, 247-268. Berlin \& New York: Mouton de Gruyter.

Brandt, Line. 2013. The communicative mind: A linguistic exploration of conceptual integration and meaning construction. Newcastle upon Tyne: Cambridge Scholars Publishing.

Brandt, Per Aage. 2005. Mental spaces and cognitive semantics: A critical comment. Journal of Pragmatics 37(10). 1578-1594.

Cánovas, Cristóbal. 2011. The genesis of the arrows of love: Diachronic conceptual integration in Greek mythology. American Journal of Philology 132(4). 553-579.

Census and Statistics Department, Hong Kong Special Administrative Region. 2017. Table No. A107 population aged 5 and over by usual spoken language and year. https://www.bycensus2016.gov.hk/en/bc-mt.html (accessed 22 April 2021). 
Choi, Lan. 2008. Chaoyu langagwang [King of funny trendy expressions]. Hong Kong: Pi Publication Ltd.

Chu, Fun. 2008. Chaoyu da jiaoxun [The lessons of trendy expressions]. Hong Kong: Wan Li Book Co. Ltd.

Coulson, Seana. 2001. Semantic leaps: Frame shifting and conceptual blending in meaning construction. Cambridge: Cambridge University Press.

Coulson, Seana \& Todd Oakley. 2000. Blending basics. Cognitive Linguistics 11(3-4). 175-196.

Coulson, Seana \& Todd Oakley. 2005. Blending and coded meaning: Literal and figurative meaning in cognitive semantics. Journal of Pragmatics 37(10). 1510-1536.

Eppe, Manfred, Ewen Maclean, Roberto Confalonieri, Oliver Kutz, Marco Schorlemmer, Enric Plaza \& Kai-Uwe Kühnberger. 2018. A computational framework for conceptual blending. Artificial Intelligence 256. 105-129.

Fauconnier, Gilles. 1994. Mental spaces: Aspects of meaning construction in natural language. Cambridge: Cambridge University Press.

Fauconnier, Gilles. 1997. Mappings in thought and language. Cambridge: Cambridge University Press.

Fauconnier, Gilles. 2001. Conceptual blending and analogy. In Dedre Gentner, Keith Holyoak \& Boicho Kokinov (eds.), The analogical mind: Perspectives from cognitive science, 255-286. Cambridge: MIT Press.

Fauconnier, Gilles \& Mark Turner. 1998. Conceptual integration networks. Cognitive Science 22(1). 133-187.

Fauconnier, Gilles \& Mark Turner. 2002. The way we think: Conceptual blending and the mind's hidden complexities. New York: Basic Books.

Glebkin, Vladimir. 2015. Is conceptual blending the key to the mystery of human evolution and cognition? Cognitive Linguistics 26(1). 95-111.

Grady, Joseph. 2005. Primary metaphors as inputs to conceptual integration. Journal of Pragmatics 37(10). 1595-1614.

Grady, Joseph, Todd Oakley \& Seana Coulson. 1999. Blending and metaphor. In Raymond Gibbs \& Gerard Steen (eds.), Metaphor in cognitive linguistics, 101-124. Amsterdam \& Philadelphia: John Benjamins.

Grygiel, Marcin. 2004. Semantic change as a process of conceptual blending. Annual Review of Cognitive Linguistics 2(1). 285-304.

Ho, Man-yee. 2005. Trendy expressions in Hong Kong Cantonese: Morphological, semantic and pragmatic analyses. Hong Kong: The University of Hong Kong MA thesis.

Hutchins, Edwin. 2005. Material anchors for conceptual blends. Journal of Pragmatics 37(10). 1555-1577.

Lakoff, George \& Mark Johnson. 1980. Metaphors we live by. Chicago: University of Chicago Press.

Lakoff, George \& Mark Johnson. 1999. Philosophy in theflesh. New York: Basic Books. 
Lakoff, George \& Zoltán Kövecses. 1987. The cognitive model of anger inherent in American English. In Dorothy Holland \& Naomi Quinn (eds.), Cultural models in language and thought, 195-221. New York: Cambridge University Press.

Linguistic Society of Hong Kong. 1997. Jyutping [Cantonese romanization scheme]. Hong Kong: Linguistic Society of Hong Kong.

Núñez, Rafael. 2005. Creating mathematical infinities: Metaphor, blending, and the beauty of transfinite cardinals. Journal of Pragmatics 37(10). 1717-1741.

Pang, Chi-Ming. 2008. Xianggang chaoyu huazhai [Anecdotes of Hong Kong trendy expressions]. Hong Kong: Subculture Publishing.

Rohrer, Tim. 2005. Mimesis, artistic inspiration and the blends we live by. Journal of Pragmatics 37(10). 1686-1716.

Sinha, Chris. 2005. Blending out of the background: Play, props and staging in the material world. Journal of Pragmatics 37(10). 1537-1554.

So, Real-Real. 2008. Xianggang chaoyu xuexi zika [Picture cards of trendy expressions in Hong Kong Cantonese]. Hong Kong: Kubrick.

So, Real-Real. 2009. Xianggang chaoyu xuexi zika er [Flash cards of trendy expressions in Hong Kong Cantonese, vol. 2]. Hong Kong: Kubrick.

Tang, Sze-Wing. 2009. Xianggang "chaoyu" goucide chutan [Word formation of Hong Kong trendy expressions]. Zhongguo Yuwen Yanjiu [Studies in Chinese linguistics] 28(2). 11-21.

Zhongli, Tumei. 2007. Food in China. Beijing: China Intercontinental Press.

Zhou, Raymond. 2010. Movies for keeps. China Daily, 28 December 2010. http:// www.chinadaily.com.cn/cndy/2010-12/28/content_11762716.htm (accessed 22 April 2021).

$\begin{array}{ll} & \text { May L-Y Wong } \\ \text { Mailing address: } & \text { School of English, The University of Hong Kong, Pokfulam Road, Hong Kong } \\ \text { Email: } & \text { maylywong @hku.hk; wlymay@gmail.com } \\ \text { Received: } & \text { September 21, } 2020 \\ \text { Accepted: } & \text { January 27, 2021 }\end{array}$




\title{
概念融合與香港粵語潮語
}

\author{
王麗賢 \\ 香港大學
}

\section{提要}

本文旨在研究九種粵語潮語, 這些潮語最初是從個人發明開始的, 但是現在已經成 為表達文化概念的既定詞彙手段。這些潮語是根據 Fauconnier 和 Turner (2002) 開發 的概念整合理論（也稱為 “融合” 理論）進行分析的。在分析中, 使用了四種不同 類型的概念集成網絡 (即, 單純形網絡、單範圍網絡、雙範圍和多範圍網絡) 來解 釋日益複雜的認知操作系統, 並以此創建潮語。在本研究討論的概念整合網絡中, 我們看到如何將熟悉的概念和關係轉換為與文化概念變化相一致的新的有意義的元 素和關係。希望透過這項研究, 表明儘管融合理論在英語中得到了廣泛的應用, 但 融合理論仍可以針對其他語言的認知機制提供一個完整而連貫的說明, 並且通過這 種認知機制，可以根據與英語不同的文化體驗來構造和解釋該地方的新詞彙。

\section{關鍵詞}

概念整合理論, 概念融合理論, 潮語, 粵語, 香港文化 